\title{
A Stirling Engine For Use With Lower Quality Fuels
}

\author{
Christopher J. Paul*, Abraham Engeda \\ Michigan State University, 428 South Shaw Lane, Room 2555, East Lansing, MI 48824, USA
}

\begin{abstract}
A Stirling engine for use with lower quality fuels was designed. The design is a derivative of the GPU-3, modified to be used with a lower combustion gas temperature $\left(900^{\circ} \mathrm{C}\right)$. It is to be used in a generator set producing 5 $\mathrm{kWe}$. The engine model used is based off of the ideal adiabatic model with decoupled loss mechanisms. Singlecylinder and two-cylinder engines were analyzed using a preheater and combustion gas recirculation (CGR). The analysis shows that the external surface area of the heater plays a very important role in determining the system performance. Maximum system efficiency was found by significantly increasing the surface area at the expense of increased dead volume. A single-cylinder configuration was found to offer the best combination of system efficiency (23.6\%) and manufacturing cost.
\end{abstract}

Keywords: Stirling Engine; Lower Quality Fuels; Surface Area; Combustion Gas Recirculation

\section{Introduction}

Currently there is a lot of interest in increasing the use of renewable fuels from biomass and unconventional fuels such as municipal waste as alternatives to fossil fuels. Gas or steam turbines are usually employed in large scale generation of electricity, while at smaller scales, internal combustion engines, whether compression or spark ignition, are employed. They all operate acceptably well at higher temperatures that fossil fuels can reach. At lower temperatures and smaller scales (less than $100 \mathrm{~kW}$ ), the advantages of these modes of generation are significantly diminished. Additionally, they are more susceptible to problems caused by the particulates generated by the use of unconventional fuels. An external combustion engine such as the Stirling engine offers the ability to use unconventional fuels without these drawbacks.

Fuels that have higher levels of impurities and lower heating values are considered to be lower quality fuels. Table 1 shows heating values and impurity content for some representative fuels. Pure methane and eastern USA bituminous coal are considered high quality fuels.

\begin{tabular}{|c|c|c|c|c|}
\hline Fuel & $\begin{array}{c}\text { Higher Heating } \\
\text { Value } \\
(\mathrm{MJ} / \mathrm{kg})\end{array}$ & $\begin{array}{c}\text { Lower Heating } \\
\text { Value } \\
(\mathrm{MJ} / \mathrm{kg})\end{array}$ & $\begin{array}{c}\text { Moisture Content } \\
(\% \text { by weight })\end{array}$ & $\begin{array}{c}\text { Ash Content } \\
(\% \text { by weight })\end{array}$ \\
\hline Methane $^{1}$ & 56 & 50 & - & - \\
\hline $\begin{array}{c}\text { Eastern USA } \\
\text { bituminous coal }^{2}\end{array}$ & 30 & - & 6.0 & 9.7 \\
\hline $\begin{array}{c}\text { Western USA } \\
\text { subbituminous coal }\end{array}$ & 19 & - & 30.4 & 9.2 \\
\hline Hardwoods $^{2}$ & 20 & 10 & 50 & 2.1 \\
\hline Agricultural $^{2}$ & 19 & 13 & 30 & 5.9 \\
\hline Municipal waste $^{3}$ & 10 & - & 30 & 36 \\
\hline
\end{tabular}

Table 1

Properties of Lower Quality Fuels

${ }^{1}$ Turns, 2000

${ }^{2}$ Easterly and Burnham, 1996

${ }^{3}$ Wiltsee et al, 1993

In the sections that follow, a brief description of the research project is presented. Next the methodology for modelling the Stirling engine and the complete electrical generation system is provided. Finally, the results of the design analysis for a system producing a net of $5 \mathrm{kWe}$ are offered.

* Corresponding author: Tel.: +15174025812

Email address: paulchri@msu.edu 


\section{Background}

The goal of this research is to develop a Stirling engine based electricity generation system that uses existing, mature technologies, does not rely on high quality petroleum based fuels, and is intended for use in military applications. One such application is part of the self-sustaining wastewater treatment system for forward operating bases (Liao, 2012). Various fuels maybe used, including biogas, wood, pellets made from other biomass, coal, and garbage. It may also be used with solar heating. The specific fuel would necessitate a unique combustor and possibly a particulate filter. The complete system needs to be truck transportable.

The specific engine to be used is a derivative of the General Motors Ground Power Unit-3 (GPU-3). The GPU-3 was developed for the U.S. Army as a silent generator for use in Vietnam. It is a single cylinder $\beta$-type, using a tube bundle heater, a water-air radiator, and rhombic drive. Using hydrogen as the working fluid, it produced up to $9 \mathrm{~kW}$ shaft power. A handful of prototypes were built and trialed but it was not accepted into service. Its dimensions and performance have been extensively documented in the literature, for example Thieme, 1979 and 1981, Johnson, 1981, and Martini, 1983.

The complete system needs to produce a net $5 \mathrm{kWe}$. The temperature of the products of combustion exiting the combustor is to be $900^{\circ} \mathrm{C}$. The adiabatic flame temperature needs to be below the point at which ash begins to melt $\left(1,250^{\circ} \mathrm{C}\right)$ if such fuels as wood and garbage are used (Pålsson, 2003). The dimensions of the GPU-3 engine are changed to better suit the lower heater temperatures. Two-cylinder versions are investigated as well, being either in parallel or staged in a simplified Fauvel-Stirling arrangement (Walker, 1992). To increase the thermal efficiency and reduce NOx emission, a combustion gas recirculation (CGR) system is added. CGR is a variant of exhaust gas recirculation (EGR). (Walker, 1994)

The original GPU-3 was designed to run on number 1 diesel fuel. The temperature of the products of combustion was about $2100^{\circ} \mathrm{C}$. (Johnson, 1981) The proposed derivative of the GPU-3 is to operate using a combustion gas temperature of only $900^{\circ} \mathrm{C}$. Both engines produce approximately the same level of power, but supplying the necessary rate heat $(\dot{\mathrm{Q}})$ input to the derivative engine is significantly more difficult due to the lower gas temperature. Additionally, the lower gas temperature results in a lower heater tube temperature, reducing the engine's efficiency. Therefore the rate of heat input needs to increase as temperature drops to achieve the necessary power output. Equation (1) is Newton's law of heating:

$$
\phi=U \cdot A \cdot L M T D
$$

From Equation (1), the convection coefficient (U) is a function of the fluid velocity. It is limited by the need to keep fan power consumption reasonable. The Log-mean-temperature-difference (LMTD) is determined by the gas temperature and tube temperature, which in turn is a function of the fluid velocity. Only the surface area (A) can be increased significantly.

The other effect of the reduced combustion temperature and heater tube temperature is the need for a larger swept volume to produce the necessary amount of power. Using the ideal Stirling thermodynamic cycle (isothermal compression/expansion and isochoric heat addition/rejection) as a guide, the amount of work produced per cycle can be shown to be (Martini, 1983):

$$
W=m \cdot R \cdot \ln (r) \cdot\left(T_{\theta}-T_{e}\right)
$$

where $\mathrm{W}$ is work per cycle $\mathrm{m}$ is the mass of gas

$\mathrm{R}$ is the gas constant $r$ is the compression ratio

$\mathrm{T}_{\mathrm{e}}$ is the expansion space temperature

$\mathrm{T}_{\mathrm{c}}$ is the compression space temperature.

As the temperature of the expansion space is reduced, the amount of work done per pass is reduced. The expected increase of the heater size will result in a lower compression ratio, further reducing the net work. As a result, the swept volume of the engine needs to increase considerably to produce the required power.

Hoegel et al (2013) performed a theoretical analysis of the operating and geometric parameters of lowtemperature difference Stirling engines. The engine was an alpha type using helium at a mean pressure of $5 \mathrm{MPa}$. The engine speed and piston phase angle were varied to find optimum heater, cooler and regenerator configurations for a two heat source temperatures: $150^{\circ} \mathrm{C}$ and $750^{\circ} \mathrm{C}$. The software Sage was employed, which uses a quasi 1-D CFD model. Mechanical losses including friction were not included. The number of heater and cooler tubes was 
found to be between 2.5-3 times more at the low temperature, while the heater and cooler tube lengths at the low temperature were about $2 / 3$ of the length of the high temperature tubes. The regenerator length was found to be nearly the same, while its porosity was higher for the low temperature. The proposed derivative of the GPU-3 should have heater tube temperatures in the middle of the range of the two temperatures used in this study.

Aksoy and Cinar (2013) investigated the effect of increasing heater surface area on a moderate-temperature difference Stirling engine. The Stirling engine was a beta type with rhombic drive and a smooth cylindrical heater. The hot end temperature was kept at $673 \mathrm{~K}$ and the engine operated using air at atmospheric pressure. The internal surface area of the heater was increased 2.5 times by the addition of longitudinal slots. The work per cycle increased by a factor of 1.5 .

Podesser (1999) reports on the design and use of a Stirling engine for use with biomass. The engine is a twincylinder alpha type. The crank mechanism is from a motorcycle engine. The engine runs on air or nitrogen at a mean pressure of $33 \mathrm{bar}$ and $600 \mathrm{rpm}$. The temperature of the products of combustion are $1000^{\circ} \mathrm{C}$. The engine produces $3.2 \mathrm{~kW}$ of shaft power while receiving $12.5 \mathrm{~kW}$ of heat. The piston swept volume is $840 \mathrm{~cm}^{3}$. The heater tube bundle is estimated to have 150 tubes at a length of $70 \mathrm{~cm}$. The proposed derivative of the GPU-3 should be of similar, albeit smaller, size due to the higher efficiency of the rhombic drive and hydrogen.

\section{Methodology}

The complete engine plus auxiliaries is shown in Figure 1. The components include the Stirling engine, a fan, a heat exchanger used as a preheater, a combustor, a combustion gas recirculation (CGR) system, and a fuel pump. Included within the Stirling engine are the alternator, heater, cooler, and water-to-air radiator (heat exchanger). The fan supplies the mass flow rate of atmospheric air to the system with a minimal pressure increase. The air is then heated in the preheater using the hot exhaust gases coming from the engine. The combustor burns the fuel increasing the air and CGR gas mixture temperature to its operating point. The resulting high temperature combustion gases pass over the heater of the Stirling engine, transferring the necessary energy to drive the engine. The CGR system returns part of the exhaust gases to be reheated and reused in the combustor. The remaining exhaust goes through the preheater.

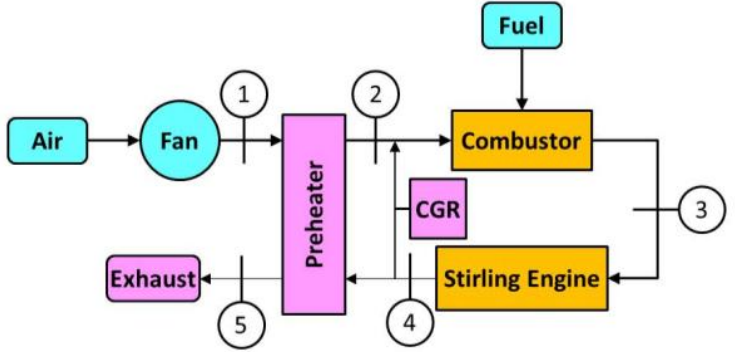

Figure 1

Complete System

The fuel for this particular analysis is biogas produced from digestion of food and human waste. It consists of $55 \%$ methane, $43 \%$ carbon dioxide, and $2 \%$ water vapor by volume. The presence of the carbon dioxide and water vapor may be beneficial in reducing NOx emissions. See Lee et al (2001) and Zhao et al (2002). Using NASA's Chemical Equilibrium with Applications (CEA) program and an equivalence ratio, air-fuel mass ratio/stoichiometric air-fuel mass ratio, $(\lambda)$ of 1.1, the adiabatic flame temperature is calculated to be $2005 \mathrm{~K}$. The amount of CGR is estimated to be at least $233 \%$ of inlet mass flow rate to keep the adiabatic flame temperature below $1,250^{\circ} \mathrm{C}$, using a CGR gas temperature of $650^{\circ} \mathrm{C}$. The lower heating value (LHV) of this biogas is 15,705 $\mathrm{kJ} / \mathrm{kg}$ fuel.

The engine model to be employed is based off of the Stirling engine model described in Paul and Engeda, 2014, which uses a development of the ideal adiabatic model (Urieli and Berchowitz, 1984). The decoupled losses include flow dissipation, non-ideal regenerator loss, appendix gap loss, thermal shorts and gas circuit hysteresis. The appendix gap is modelled as a non-ideal regenerator. The flow dissipation in the regenerator is multiplied by a factor of two to account for the oscillating flow (Ju et al, 1998). The overall pressure drop is multiplied by a factor of $4 / 3$ to include the gradient of the divergence of velocity term missing from the momentum equation. The performance of this model was validated using the experimental data for the GPU-3 (Figure 3-8 in Martini, 1983) and found to be within $\pm 6.6 \%$ for power and $+2.2 /-8.5 \%$ for efficiency at a mean engine pressure of $6.9 \mathrm{MPa}$. 
The fan is modeled as an adiabatic compressor. The work of the fan is calculated assuming isentropic compression and constant specific heats. The isentropic efficiency is assumed to be $80 \%$.

The pressure ratio of the fan is determined from the known atmospheric pressure and exit pressure which is the sum of the pressure losses through each component. The pressure losses through the preheater and over the Stirling engine heater are estimated using the method of Kays (1964). The external friction factor for the heater tube bundle is assumed to be 1 .

The preheater is modeled as a plate-fin compact heat exchanger. The configuration used is the plain plate-fin surface 46.46T and its measured performance is given in Figure 10-37 of Kays (1964). Its size is a compromise between increasing the outlet temperature of the cold air stream and maintaining a reasonable pressure loss.

The combustor is a non-premixed type for use with the biogas. The primary air stream is supplied at a rate to maintain an equivalence ratio $(\lambda)$ of 1.1. The secondary air or CGR exhaust dilutes the primary to reduce the temperature to the desired $900^{\circ} \mathrm{C}$. The maximum amount of CGR exhaust is limited to maintain the necessary equivalence ratio. The combustor is modelled using a steady flow control volume. The mass of fuel added is modelled as an equivalent mass of air; the energy released by combustion is found using the LHV.

The Stirling engine cooler is modeled as a compact heat exchanger arranged in a staggered tube bank. A constant tube surface temperature is assumed. The heat from the cooler is rejected to the atmosphere by the radiator, another compact heat exchanger. The ambient air temperature is assumed to be $25^{\circ} \mathrm{C}$. The radiator configuration is a bundle of finned tubes (surface 8.0-3/8T) and its experimentally determined performance is shown in Figure 10-83 of Kays (1964). The amount of heat transfer, inlet water and inlet air temperatures are known from the engine analysis. The exit temperatures are calculated using the log-mean-temperature difference and overall heat transfer coefficient method for a thermal circuit from the cooler tube surface of the engine to the atmospheric air. The size of the finned tube heat exchanger is chosen by minimizing the power consumption of both the water pump and the fan for moving the air across the heat exchanger.

The alternator is modeled as having an efficiency of $90 \%$. It is to be incorporated in a sealed crankcase with the engine to reduce working gas losses. The fan and cooling system (water pump and radiator fan) are driven by electric motors, consuming part of the electricity produced.

\section{Results and Discussion 4.1 Effect of Operating Conditions on GPU-3}

The performance of the GPU-3 was investigated as the combustor gas temperature was reduced. Figure 2 shows the engine indicated efficiency and the total system efficiency. The mean pressure was $6.9 \mathrm{MPa}$; the engine speed was $30 \mathrm{~Hz}$ using hydrogen. The heater tube temperature was adjusted so that the system produced the maximum amount of power. The system has an efficiency of $5.9 \%$ at the desired temperature of $900^{\circ} \mathrm{C}$. The indicated engine efficiency is $27.0 \%$. Note that in Figures 2-6, the highest combustor gas temperatures $(2,373 \mathrm{~K}$ and 2,173 K) are modeled using number 1 diesel fuel. The original GPU-3 operated on number 1 diesel.

Figure 3 shows the net usable power produced by the system, the power consumed by the fans and water pump, the heat supplied to the heater, the cycle heat rejection and the amount of heat added from the fuel. At 1,173 K, $1,600 \mathrm{~W}$ net are produced and $644 \mathrm{~W}$ are consumed to drive the fans and pump. The lowest possible temperature at which the GPU-3 would run is estimated to be $936 \mathrm{~K}$. 


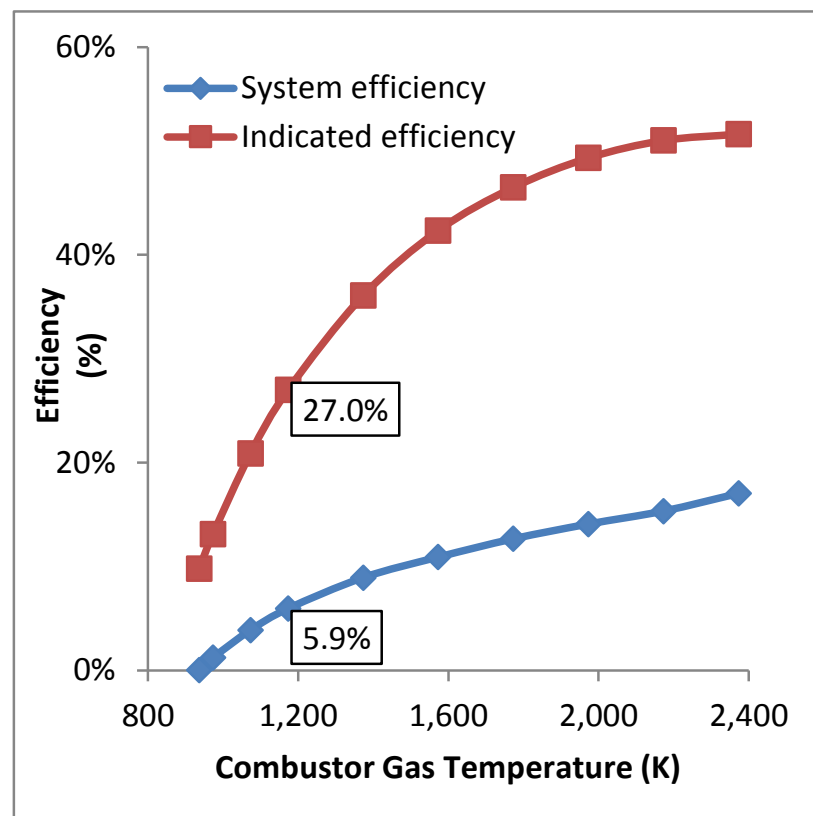

Figure 2

GPU-3 Efficiencies as Combustor Gas Temperature is Reduced

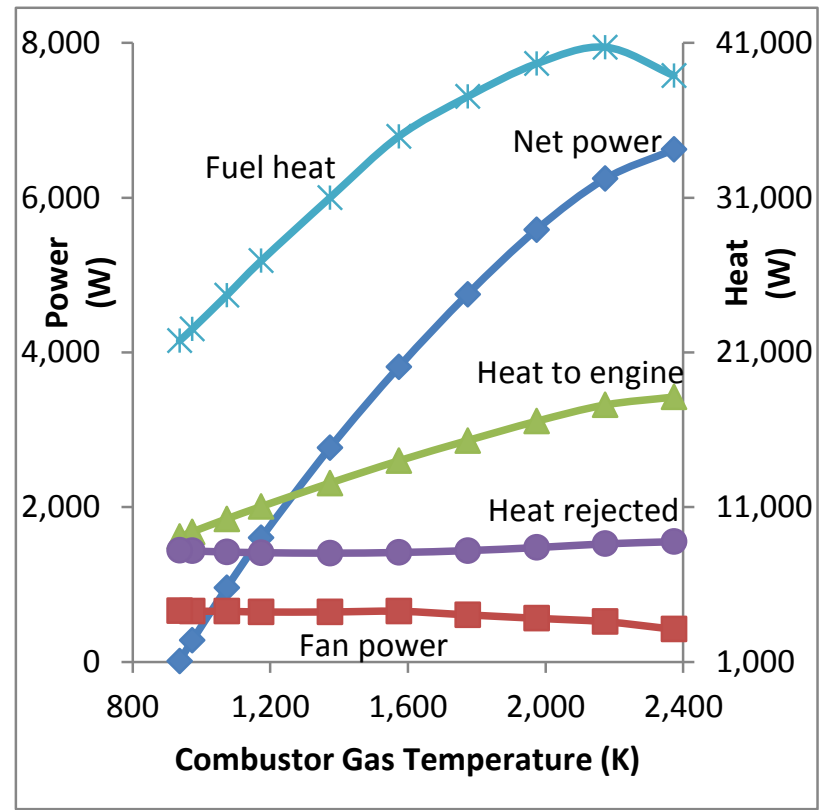

Figure 3

GPU-3 Power and Heat as Combustor Gas Temperature is Reduced

Figure 4 shows the temperature of the outer surface of the heater tube, the LMTD between the combustion gas and heater tube, and the heat transfer convection coefficient to the heater tubes as the combustion gas temperature is decreased. The LMTD is nearly constant as the tube and combustor gas temperatures decrease at about the same rate. The convection coefficient decreases. The result of this is that the heat to the engine goes down as shown in Figure 3. 


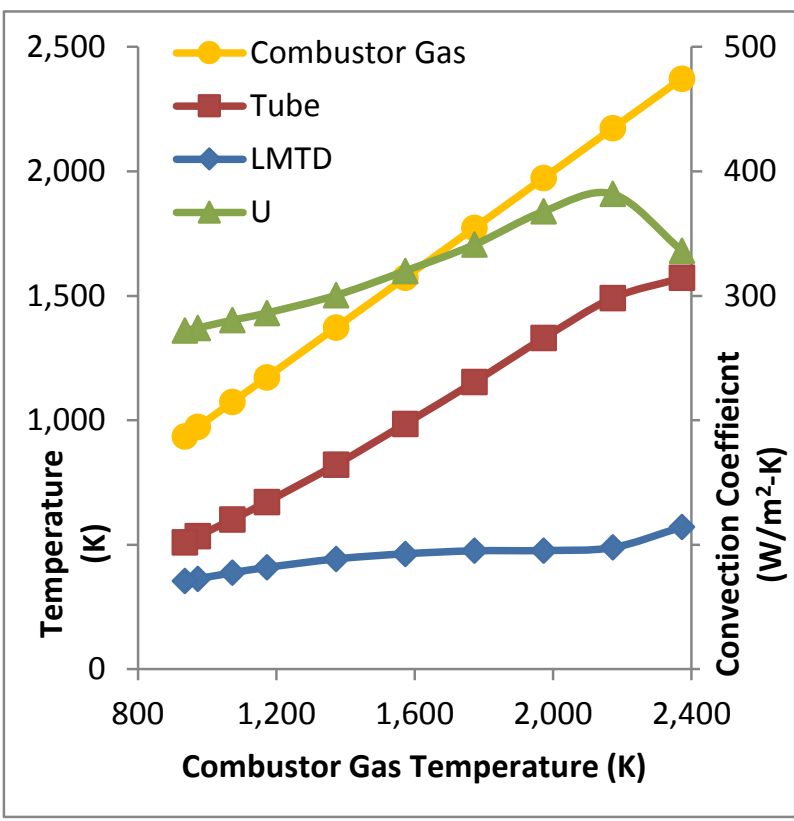

Figure 4

Figure 5 shows the total pressure drop through the system, heater and preheater. The pressure drop is $8.5 \mathrm{kPa}$ and the mass flow rate is $3,644 \mathrm{~g} / \mathrm{min}$ at a combustor temperature of $1,173 \mathrm{~K}$. This estimate of pressure loss seems reasonable since Thieme (1979) reported a pressure drop of $3.85 \mathrm{kPa}$ at a mass flow rate of $1,238 \mathrm{~g} / \mathrm{min}$ while (1981) a pressure drop of $3.23 \mathrm{kPa}$ at a mass flow rate of $762 \mathrm{~g} / \mathrm{min}$ was recorded. The pressure drop is mainly due to the heater, being proportional to $\rho u^{2}$.

Figure 6 shows the mass flow rate, the density and velocity squared through the heater. The density increases as the temperature drops. The velocity peaks then decreases with temperature. The net result is that the pressure drop through the heater follows the velocity.

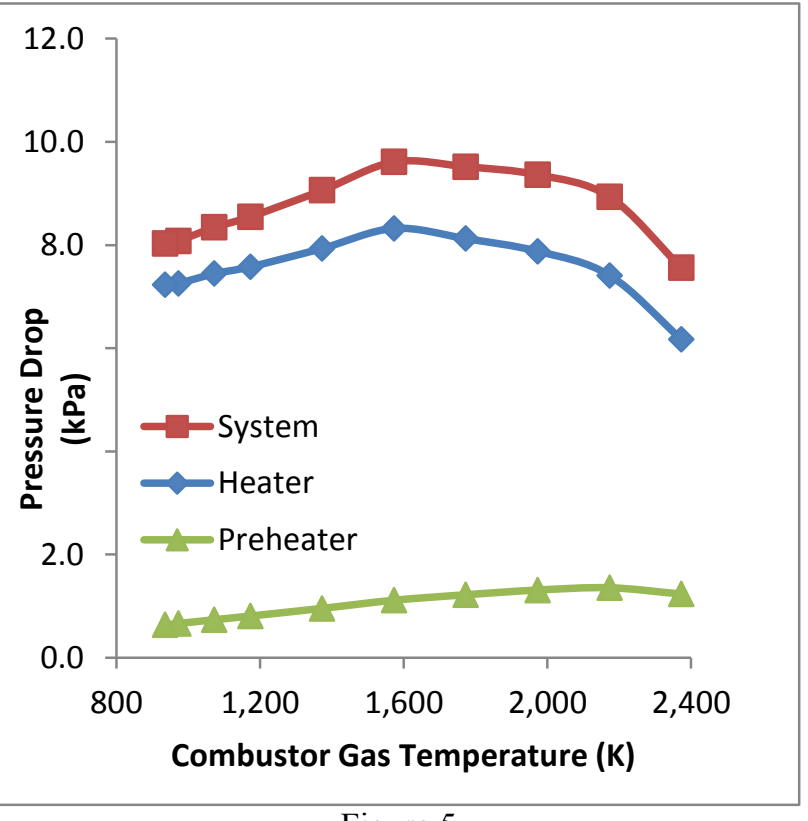

Figure 5

GPU-3 Pressure Drop as Combustor Gas Temperature is Reduced 
Figure 6

GPU-3 Mass Flow Rate, Density and Velocity ${ }^{2}$ as Combustor Gas Temperature is Reduced

Figure 7 shows the energy balance as a percent of the total heat input. The exhaust losses increase from $50 \%$ then level off. Drivetrain losses decrease slightly, while heat loss to the environment increases slightly. Power drops off, more rapidly as the temperature decreases. Cycle heat rejection goes down a small amount then increases. The amount of heat rejection is fairly constant, but as a fraction of the amount of energy added, it increases due to the decreasing engine efficiency and decreasing heat input to the engine.

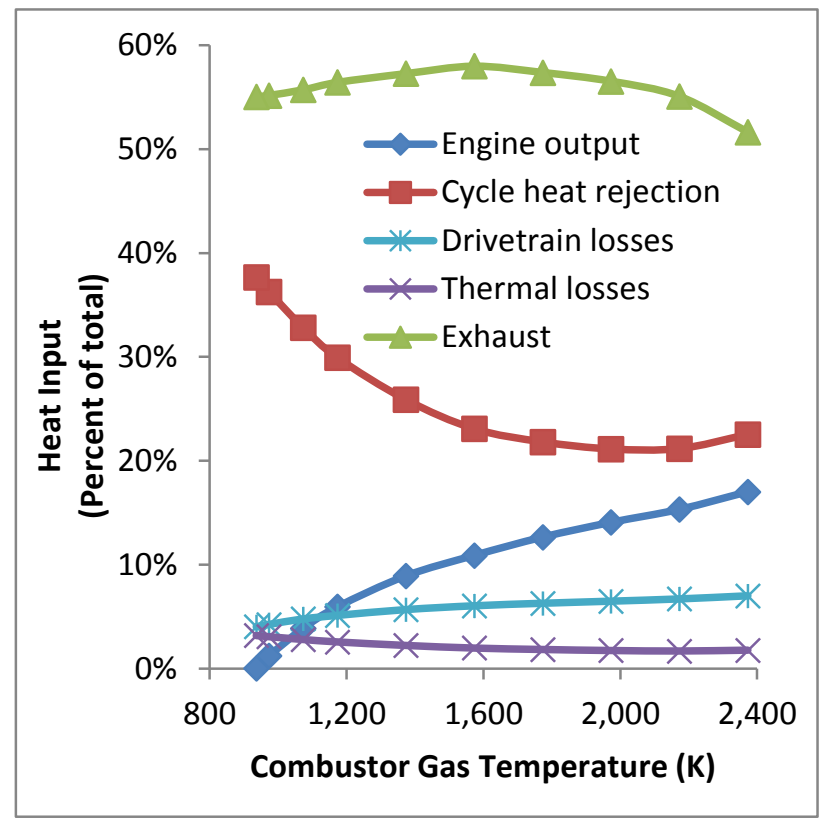

Figure 7

GPU-3 Energy Balance as Combustor Gas Temperature is Reduced 


\subsection{Single Cylinder Engine}

The performance of the unmodified GPU-3 at $900^{\circ} \mathrm{C}$ is $1,600 \mathrm{~W}$. From Figure 3, it is evident that the engine is being choked from a lack of heat input. Figure 8 shows the effects of increasing the heater surface area on net power, power consumed by the fans and pump, and the heat input to the engine. The surface area was increased by lengthening the heat transfer section of the heater tubes from $15.54 \mathrm{~cm}$ to $26.0 \mathrm{~cm}$ and by increasing the number of heater tubes from 40 to 60 . The maximum tube length is set at $26.0 \mathrm{~cm}$ which is the length as used in the United Stirling of Sweden (USS) 4-95 engines without significant problems running on hydrogen at $30 \mathrm{~Hz}$ (West, 1986). The length of the cylinder is increased to accommodate an extra row of heater tubes. The heater tubes of the GPU-3 are arranged in two staggered rows where they meet the cylinder. A third staggered row is needed for additional tubes to be used with the same diameter cylinder. Also, the height of the preheater is increased to match the extra length of the heater tubes. The maximum net power increased to $2,775 \mathrm{~W}$ from $1,600 \mathrm{~W}$. The system efficiency went from $5.9 \%$ to $9.1 \%$ while the engine's indicated efficiency increased from $27.0 \%$ to $37.1 \%$ due to the ability to maintain the heater tubes at a higher temperature, from $672 \mathrm{~K}$ to $878 \mathrm{~K}$. Despite the increase in dead volume, the system power and efficiency both improve. At the same tube temperature $(766 \mathrm{~K})$, the indicated efficiency decreases from $33.17 \%$ for 40 tubes at $15.54 \mathrm{~cm}$ to $32.83 \%$ for 60 tubes at $26.0 \mathrm{~cm}$ length. A further increase in heater tubes by a fourth row decreased the maximum power attainable.

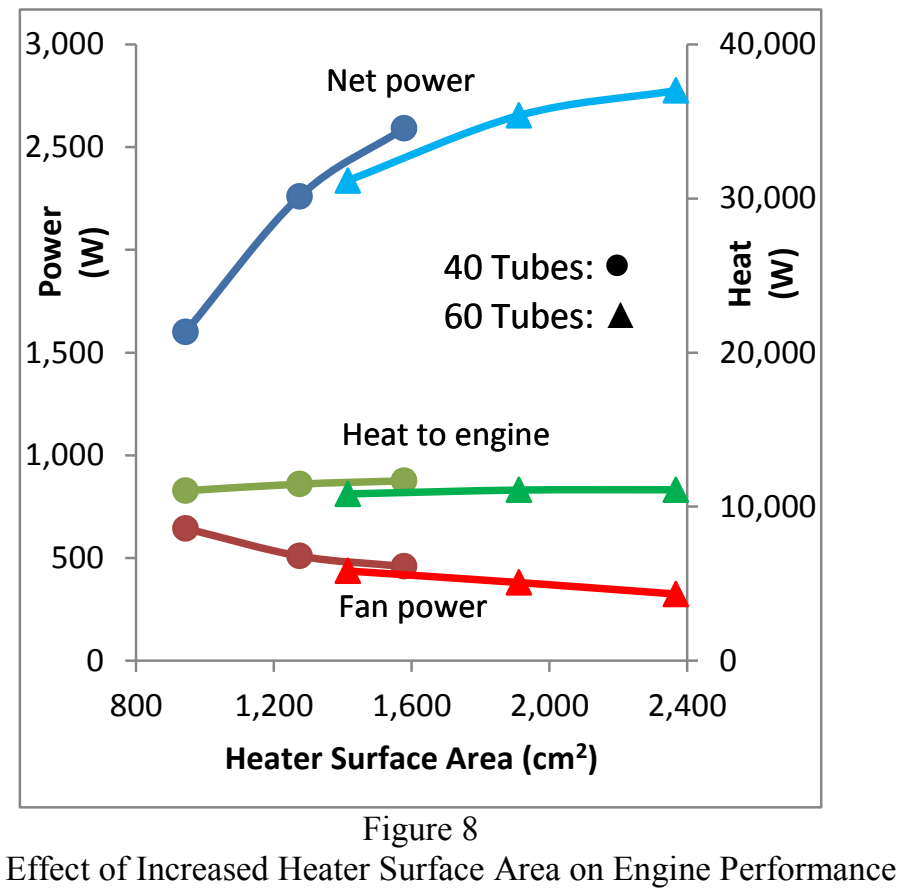

To meet the $5 \mathrm{kWe}$ power requirement, the engine must be increased in size. Since the original engine was designed to produce approximately the same power level, the dimensions of the drive mechanism are not changed. The diameter of the cylinder is increased. This allows the number of heater tubes to increase. As the number of tubes increases, the vertical heat transfer section must be located further away from the cylinder, thereby increasing the total unheated length of the tubes. The size of the preheater surrounding the heater tubes is enlarged to fit over the heater tubes and optimized to minimize the total pressure loss of both streams. The size of the regenerator canisters is also increased, maintaining the same engine-swept-volume-to-regenerator-volume ratio. The length of the cooler tubes is increased to $9.0 \mathrm{~cm}$ as used in the USS 4-95 and the number of cooler tubes is increased; maintaining the same ratio of cooler tubes-to-engine swept volume.

Figure 9 shows the net electrical power produced by the system as the piston and cylinder diameters are increased. Engines using three rows of heater tubes are able to reach the power requirement. Engines using two rows of heater tubes are not able to meet the power requirement; the maximum is $4.8 \mathrm{kWe}$. The gross power of the engine using 2 rows of heater tubes increases but at a rate that decreases with diameter, while the power consumed by the fan increases nearly linearly. The result is that the extra power produced by the engine is less than the power consumed by the fan as the engine becomes larger. 
Figure 10 shows the overall system efficiency. The engine using 3 tube rows (piston diameter of $10.87 \mathrm{~cm}$; expansion space swept volume $292 \mathrm{~cm}^{3}$ ) produces $5.0 \mathrm{kWe}$ at a system efficiency of $12.4 \%$. The maximum system efficiency occurs where the heat added to the incoming air is at a minimum. The engine using 2 tube rows (piston diameter of $12.42 \mathrm{~cm}$; expansion space swept volume $382 \mathrm{~cm}^{3}$ ) produces $4.8 \mathrm{kWe}$ at a system efficiency of $5.8 \%$. The higher efficiency of the engine with 3 tube rows is due primarily to the lower gas velocity over the heater tubes, lowering the mass flow rate $(5,422 \mathrm{~g} / \mathrm{min} \mathrm{v} .11,137 \mathrm{~g} / \mathrm{min})$, the exhaust losses and the fan power consumption. The system using the engine with 2 tube rows can achieve $5.0 \mathrm{kWe}$ by removing the preheater thereby reducing the fan power consumption and the system efficiency $(2.9 \%)$. It may also be possible to reach the power requirement using the engine with two tube rows if the engine were better optimized. Timoumi et al (2008) report that the GPU-3 may produce up to $20 \%$ more power by choosing more optimal engine dimensions; the GPU-3 derivative used here may well respond similarly.

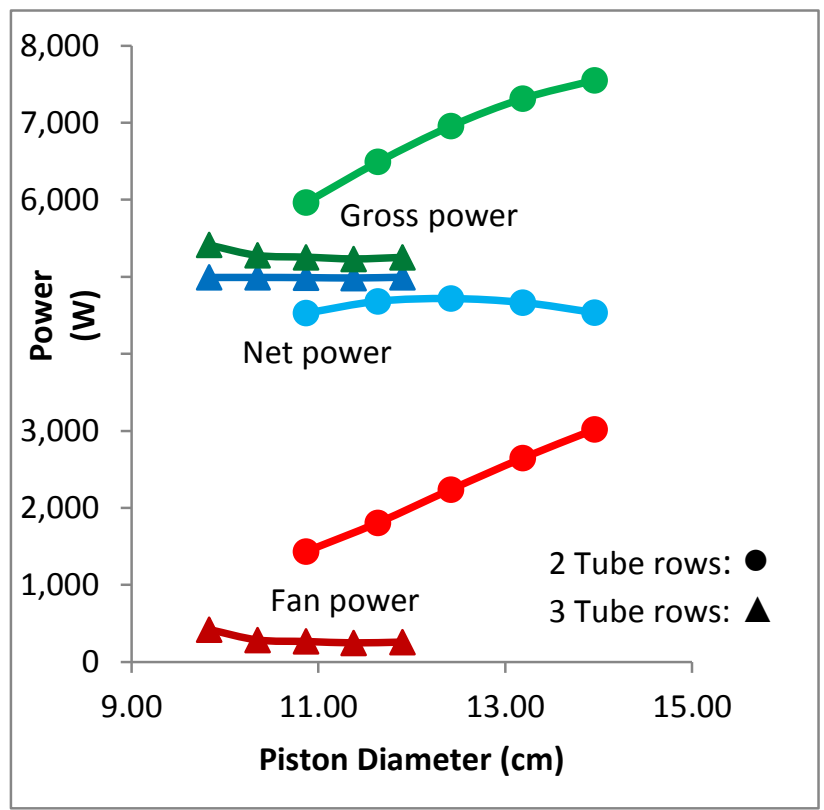

Figure 9

Effect of Increased Piston Diameter on Engine Power

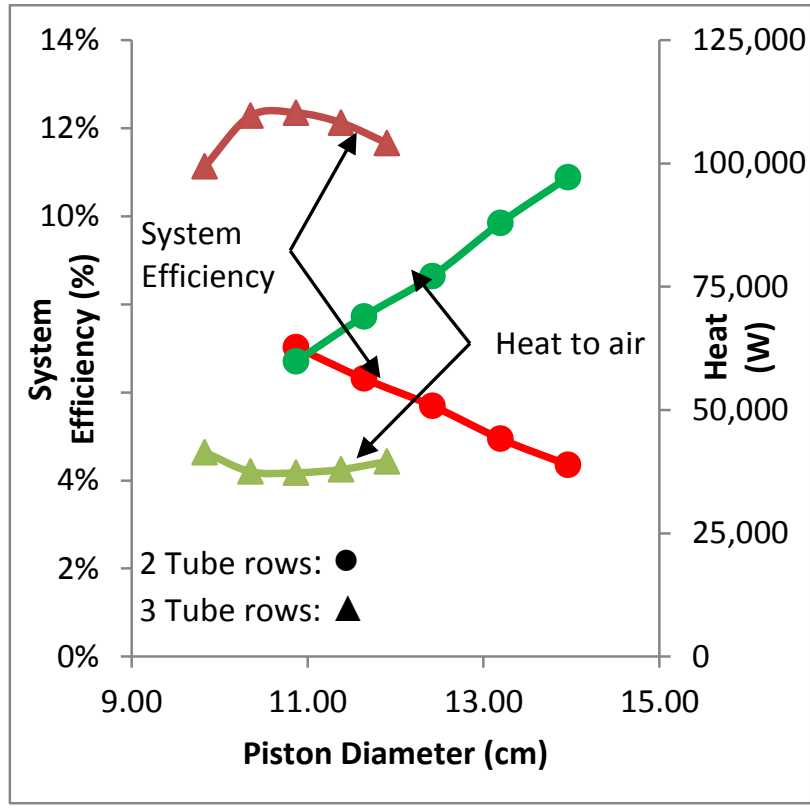

Figure 10

Effect of Increased Piston Diameter on Engine Efficiency 
Figure 11 shows the effect the gap between the heater tubes has on the system power and efficiency for the engine that uses 2 rows of heater tubes with a piston diameter of $12.42 \mathrm{~cm}$. Maximum efficiency occurs at the lowest possible tube gap. System power is maximized when the fan power consumption is minimized by increasing the gap between the heater tubes. The net power increases to $4.9 \mathrm{kWe}$ at $4.9 \%$ when the gap is $0.088 \mathrm{~cm}$ versus the $0.067 \mathrm{~cm}$ gap used on the GPU-3.

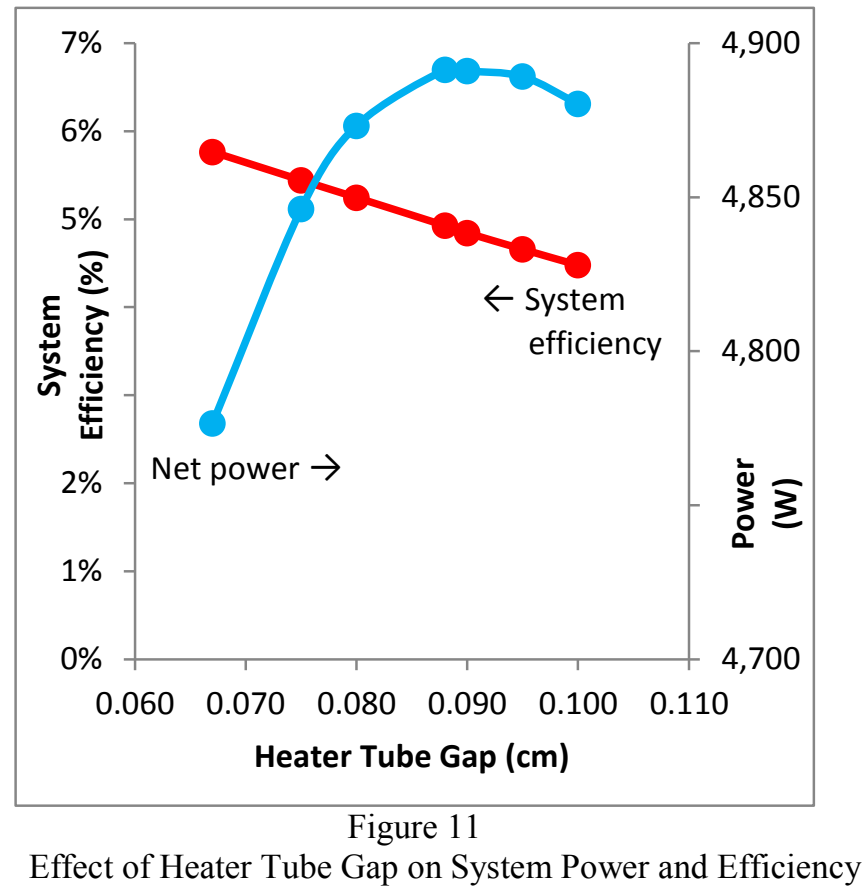

\subsection{Two Cylinder Engine}

Two single cylinder engines could be combined to produce the necessary power. Two GPU-3s with 40 heater tubes of $26 \mathrm{~cm}$ length would produce $5.0 \mathrm{~kW}$ at an efficiency of $10.4 \%$. Combining the engines together in a single crankcase and using a single preheater and radiator would produce the same performance and reduce the number of components. The complication is the extra tubing needed to route the gas to-and-from the preheater. There have been a few such engines: Philips 4-235 (Hargreaves, 1991) and the GM 4L23 (Martini, 1983). Both were large, 4 cylinder high power transportation prime movers. The 4-235 used four separate displacer-piston pairs and a rhombic drive, while the 4L23 used four interconnected double acting pistons and the crank-slider mechanism.

Figure 12 shows the power and efficiency for an engine using two cylinders in parallel. The maximum system efficiency is $15.4 \%$ for an engine using three tube rows (64 tubes) per cylinder with a piston diameter of $7.51 \mathrm{~cm}$ (139 $\mathrm{cm}^{3}$ swept volume). The maximum efficiency for two tube rows (40 tubes) is $13.7 \%$. 


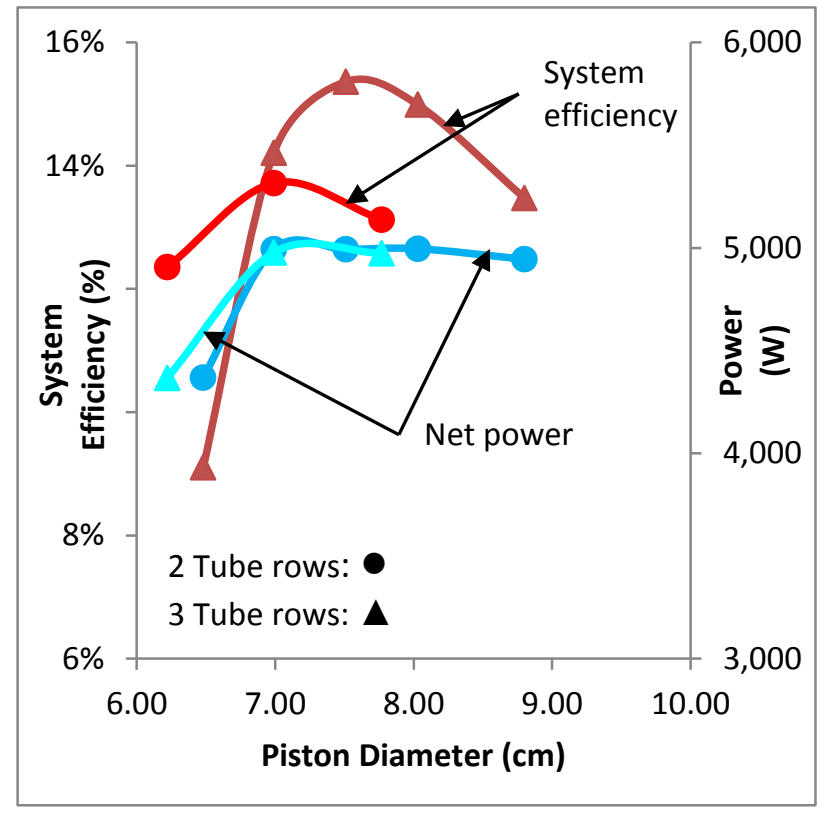

Figure 12

Performance of Two-Cylinder Engines - Parallel as Engine Size Varies

Instead of having two-cylinders in parallel, the two cylinders can be used in series, i.e. the second uses the exhaust from the first. Figure 13 shows the performance of the two-cylinder-series engine as the heater tube gap of the first engine is varied. The engine used is the same one for the two-cylinder-parallel arrangement (piston diameter $7.51 \mathrm{~cm} ; 64$ heater tubes) except that the heater tube gap for the $1^{\text {st }}$ engine is varied. For a $1^{\text {st }}$ engine heater tube gap of $0.204 \mathrm{~cm}$, both engines produce $50 \%$ of the power. The second cylinder produces the same amount of power despite the lower gas temperature because the gas is squeezed through the smaller tube gap of the second cylinder, increasing the gas velocity and the convection coefficient. When both cylinders have the same heater tube gap $(0.067 \mathrm{~cm})$, the second cylinder produces $40.7 \%$ of the power. The system efficiency is now $17.1 \%$ compared to $15.4 \%$ in parallel for essentially the same amount of hardware.

Figure 14 shows the fan consumption and the exhaust losses as the $1^{\text {st }}$ tube gap is varied. The power consumption of the fan first reaches a minimum, and then increases as the gap is increased from $0.067 \mathrm{~cm}$ to 0.204 $\mathrm{cm}$, while exhaust losses increase as the first engine heater tube gap is increased. Minimizing exhaust losses maximizes system efficiency. The exhaust losses decrease due to the mass flow rate of gas decreasing. As for the single cylinder engine, there is a heater tube gap for the first cylinder that minimizes fan consumption and maximizes net power; in this case $0.115 \mathrm{~cm}$. 


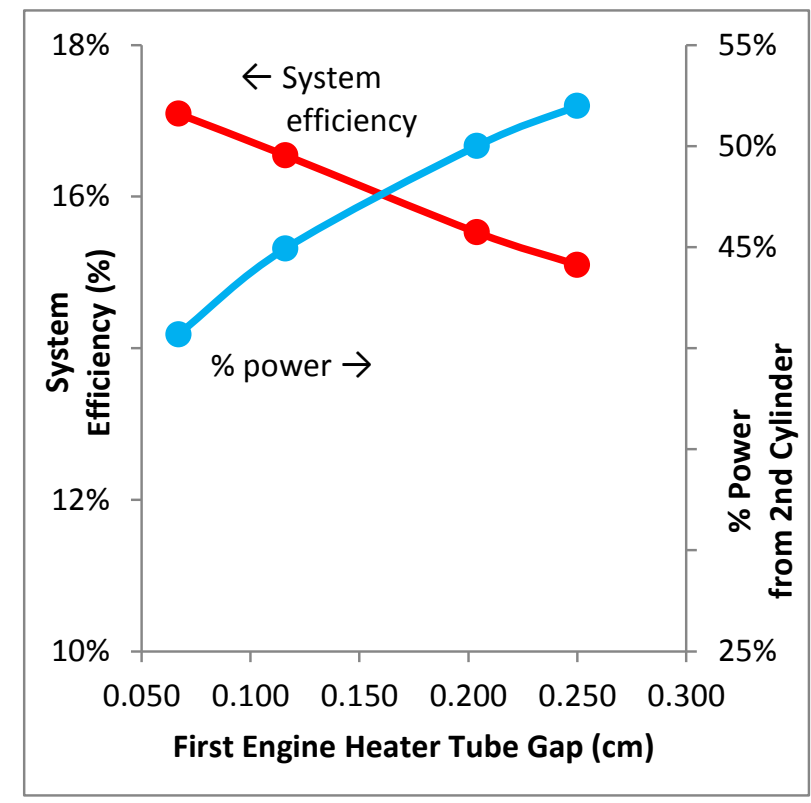

Figure 13

Effect of First Engine Heater Tube Gap on System Efficiency and Power Produced from $2^{\text {nd }}$ Engine

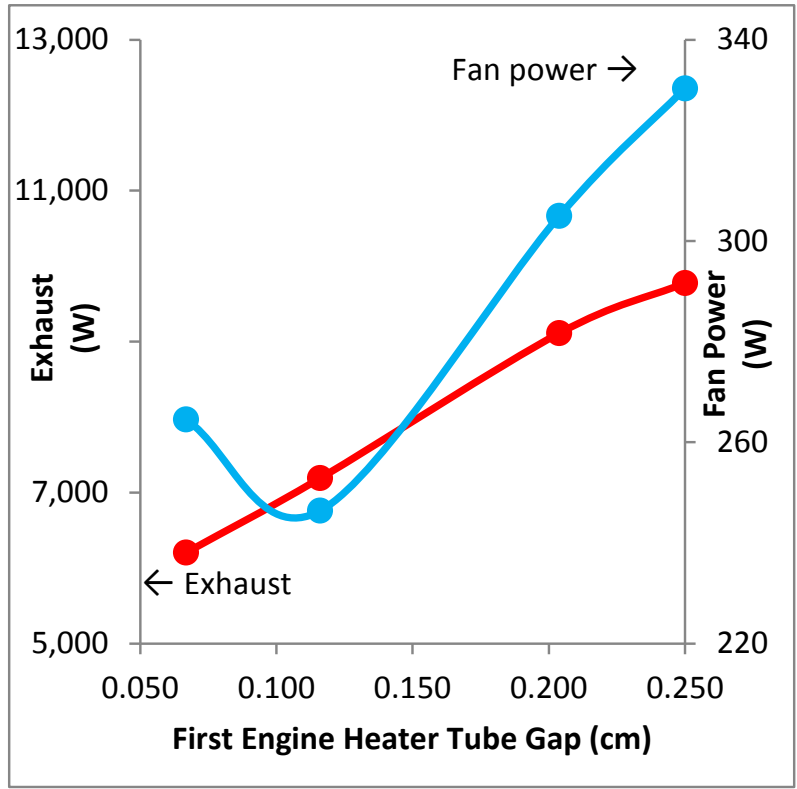

Figure 14

Effect of First Engine Heater Tube Gap on Exhaust Losses and Fan Power Consumption

Figure 15 shows the system efficiency as the size of the two cylinders is varied. The maximum efficiency occurs when the heat absorbed by the air is at a minimum. The engine with a piston diameter of $6.48 \mathrm{~cm}$ was only able to produce a maximum of $4.35 \mathrm{~kW}$, not the necessary $5 \mathrm{kWe}$. Since the system efficiency improved by having the $1^{\text {st }}$ cylinder produce more power, the size of the $1^{\text {st }}$ cylinder was increased and the $2^{\text {nd }}$ was decreased. The efficiency did improve on the order of $0.1 \%$ but that is not significant enough to be important. 


\subsection{Effect of Regenerator}

All of the engines modelled have had regenerators sized so that the ratio of the swept volume-to-regenerator volume has been kept the same as the original GPU-3. From Paul and Engeda (2014), the regenerator is the largest source of loss, both thermal and flow dissipation. Figure 16 shows the effect of increasing the regenerator volume on the system efficiency. The regenerator length was held constant and its diameter was increased. The maximum system efficiencies for all engines increase. The largest increase is for the single-cylinder two-tube-row engine, from $5.7 \%$ to $12.7 \%$. The highest efficiency is now $19.8 \%$ for the two-cylinder series engine. As the regenerator diameter increases, the power output decreases due to the increase in dead volume; the heater tube temperature has to increase to maintain the necessary power output. Beyond a certain point, the system efficiency peaks as the fan power consumption increases faster than the engine output. Organ (1997) suggested that the GPU-3 regenerator was too small, on the order of 50\% of the ideal size, while the USS 4-95 (P-40) was nearly ideal. Using the swept volume-toregenerator void volume of the 4-95 as a guide limits the size of the regenerators for the single cylinder engines. The maximum efficiencies for the two-cylinder engines occur before the limit. The maximum efficiency is now $15.9 \%$ and $11.4 \%$ for the 3 -tube and 2 -tube single-cylinder engines respectively. 


\subsection{Combustion Gas Recirculation}

All of the engine/system combinations thus far have used a preheater but no combustion gas recirculation system. Table 2 shows the effect of adding CGR (\% of inlet mass flow rate) to the single-cylinder and two-cylinder engines. The amount of CGR is the maximum possible while keeping $\lambda$ at 1.1. Adding CGR increases system efficiency to a maximum of $24.7 \%$ for the two-cylinder series engine. CGR has a larger effect on systems with larger mass flow rates; hence the larger increase in efficiency for the two-cylinder parallel system compared to the two-cylinder series system. If the single-cylinder two-tube row engine had its regenerator at the size that maximized system efficiency, the increase due to CGR would be larger than for the single-cylinder three-tube row engine. The main effect of the CGR is to reduce the amount of fuel needed and the exhaust losses. The reduction in fan power consumption is due to the pressure drop being reduced since the mass flow rate through the preheater is smaller.

\subsection{System Design}

The performances of the systems using engines with three-heater tube rows per cylinder are similar. The twocylinder configurations offer a small advantage efficiency wise but the engine would cost nearly twice as much. The single-cylinder three-heater-tube row engine offers the best compromise between performance and manufacturing cost and is therefore the better choice. Table 3 shows the system operating point. The dimensions for the singlecylinder, three-heater-tube row engine are given in the Appendix. 


\begin{tabular}{|c|c|c|c|c|c|}
\hline Engine & $\begin{array}{c}\text { Mass Flow Rate } \\
\text { (g/min) }\end{array}$ & $\begin{array}{c}\text { System } \\
\text { Efficiency } \\
(\%)\end{array}$ & $\begin{array}{l}\text { Fan } \\
\text { (W) }\end{array}$ & $\begin{array}{l}\text { Fuel Heat } \\
\qquad(\mathrm{W})\end{array}$ & $\begin{array}{c}\text { Exhaust Losses } \\
\text { (W) }\end{array}$ \\
\hline $\begin{array}{c}\text { 1-Cylinder } \\
\text { (2 tube rows) }\end{array}$ & 5,935 & 11.4 & 456 & 44,238 & 18,975 \\
\hline $\begin{array}{l}+ \text { CGR } \\
(669 \%)\end{array}$ & 5,797 & 18.3 & 371 & 27,342 & 2,220 \\
\hline $\begin{array}{l}\text { 1-Cylinder } \\
\text { (3 tube rows) }\end{array}$ & 4,258 & 15.9 & 155 & 31,542 & 12,047 \\
\hline $\begin{array}{l}+ \text { CGR } \\
(614 \%)\end{array}$ & 4,217 & 23.6 & 132 & 21,206 & 1,750 \\
\hline $\begin{array}{c}\text { 2-Cylinder } \\
\text { Parallel }\end{array}$ & 4,025 & 17.9 & 166 & 28,052 & 8,044 \\
\hline $\begin{array}{l}+ \text { CGR } \\
(614 \%)\end{array}$ & 3,935 & 24.4 & 111 & 20,636 & 1,394 \\
\hline $\begin{array}{c}\text { 2-Cylinder } \\
\text { Series }\end{array}$ & 3,093 & 19.8 & 215 & 25,237 & 5,373 \\
\hline $\begin{array}{l}+ \text { CGR } \\
(456 \%)\end{array}$ & 3,056 & 24.7 & 169 & 20,286 & 1,178 \\
\hline
\end{tabular}

Table 2

The Effect of Adding CGR on System Performance for One- and Two-Cylinder Engines 


\begin{tabular}{|c|c|c|}
\hline & $\begin{array}{c}\text { Mass Flow Rate } \\
(\mathrm{g} / \mathrm{min})\end{array}$ & $\begin{array}{c}\text { Temperature } \\
(\mathrm{K})\end{array}$ \\
\hline Inlet air (1) & 509 & 298 \\
\hline Preheated air (2) & 509 & 298 \\
\hline Fuel & 81 & 1,173 \\
\hline Combustor exit (3) & 4,217 & 940 \\
\hline Heater exit (4) & 4,217 & 940 \\
\hline CGR & 3,627 & 473 \\
\hline $\begin{array}{c}\text { Exhaust (5) } \\
\text { Heater pressure drop } \\
\text { (kPa) }\end{array}$ & 590 & 0.672 \\
\hline Preheater pressure drop, both streams (kPa) & & 0.138 \\
\hline
\end{tabular}

Table 3

System Operating Point

(1) refer to Figure 1) 


\section{Conclusions}

A Stirling engine for use with lower quality fuels was designed. The design is a derivative of the GPU-3, modified to be used with lower combustion gas temperatures $\left(900^{\circ} \mathrm{C}\right)$. It is to be used in a generator set producing 5 $\mathrm{kWe}$. The engine model used is based off of the ideal adiabatic model with decoupled loss mechanisms. Singlecylinder and two-cylinder engines were analyzed using a preheater and combustion gas recirculation (CGR). The analysis shows that the external surface area of the heater plays a very important role in determining the system performance. Maximum system efficiency was found by significantly increasing the surface area at the expense of increased dead volume. A single-cylinder configuration was found to offer the best combination of system efficiency $(23.6 \%)$ and manufacturing cost.

\section{Acknowledgment}

This research is funded by a combined grant (ER-2215) from the United States Department of Energy and Department of Defense. 


\section{References}

1. Aksoy, F., and Cinar, C. 2013. Thermodynamic analysis of a beta-type Stirling engine with rhombic drive mechanism. Energy Conversion and Management. 75. 319-324.

2. Easterly, J.L. and Burnham, M. 1996. Overview of Biomass and Waste Fuel Resources for Power Production. Biomass and Bioenergy, 10(2-3):79-92.

3. Hargreaves, C.M., 1991. The Philips Stirling Engine. Elsevier, New York.

4. Hoegel, B., Pons, D., Gschwendtner, M., Tucker, A., and Sellier, J. 2013. Thermodynamic peculiarities of alpha-type Stiring engines for low-temperature difference power generation: Optimisation of operating parameters and heat exchangers using a third-order model. J. Mech. Eng. Sci. 0(0) 1-12.

5. Johnson, D.C., Congdon, C.W., Begg, L.L., Britt, E.J., and Thieme, L.G. 1981. Jet Impingement Heat Transfer Enhancement for the GPU-3 Stirling Engine. NASA-TM-82727.

6. Ju, Y., Jiang, Y., and Zhou, Y. 1998. Experimental study of the oscillating flow characteristics for a regenerator in a pulse tube cryocooler. Cryogenics 38(06) 649-656.

7. Kays, W.M., and London, A.L. 1964. Compact Heat Exchangers. $2^{\text {nd }}$ Ed. McGraw-Hill. New York.

8. Lee, C.E., Lee, S.R., Han, J.W., and Park, J., 2001. Numerical Study on effect of $\mathrm{CO}_{2}$ addition in flame structure and $\mathrm{NO}_{\mathrm{x}}$ formation of $\mathrm{CH}_{4}$-air counterflow diffusion flames. Int. J. Energy Res., 25:343-354.

9. Liao, W. 2012. A Self-Sustaining Solar-Bio-Nano Based Wastewater Treatment System for Forward Operating Bases. Michigan State University. Presentation. East Lansing, MI, USA.

10. Martini, W.R. 1983. Stirling Engine Design Manual, $2^{\text {nd }}$ Ed. NASA CR-168088. DOE/NASA, Washington D.C.

11. NASA Chemical Equilibrium with Applications (CEA). www.grc.nasa.gov/WWW/CEAWeb/

12. Organ, A.J. 1997. The Regenerator and the Stirling Engine. Mechanical Engineering Publications Ltd, London.

13. Pålsson, M. and Henrik, C., 2003. Development of a Wood Powder Fuelled 35 kW Stirling CHP Unit. Proc. $11^{\text {th }}$ Int. Stirling Engine Conf., 221-230.

14. Paul, C.J. and Engeda, A. 2014. Modeling a Complete Stirling Engine. Energy http://dx.doi.org/10.1016/j.engergy.2014.11.045.

15. Podesser, E. 1999. Electricity Production in Rural Villages with a Biomass Stirling Engine. Renewable Energy. 16. 1049-1052.

16. Thieme, L.G. 1979. Low-Power Baseline Test Results for the GPU-3 Stirling Engine. NASA-TM-79103.

17. Thieme, L.G. 1981. High-Power Baseline and Motoring Test Results for the GPU-3 Stirling Engine. NASATM-82646.

18. Timoumi, Y. Tlili, I. and Nasrallah, S.B. 2007. Design and performance optimization of GPU-3 Stirling Engines. Energy 33. 1100-1114.

19. Turns, S. 2000. An Introduction to Combustion. $3^{\text {rd }}$ Ed. McGrall Hill, New York.

20. Urieli, I. and Berchowitz, D.M. 1984. Stirling Cycle Engine Analysis. Adam Hilger Ltd, Bristol.

21. Walker, G., Kremer, J., Fauvel, O.R., Reader, G., , and Bingham, E.R. 1992. Stirling Bottoming Cycle for the Gas Turbine Exhaust Streams of Pipeline Compressor Stations. SAE Technical Paper 929393.

22. Walker, G., Reader, G., Fauvel, O.R., and Bingham, E.R. 1994. The Stirling Alternative. Gordon and Breach, Yverdon, Switzerland.

23. West, C.D. 1986. Principals and Applications of Stirling Engines. Van Nostrand Reinhold Company, Ltd, New York

24. Wiltsee, G.A. Jr, Easterly, J., Vence, T. et al. 1993. Strategic Analysis of Biomass and Waste Fuels for Electrical Power Generation. Electric Power Research Institute, EPRI-TR-10277.

25. Zhao, D., Yamashita, H., Kitagawa, K., Arai, N., and Furuhata, T. 2002. Behavior and Effect of $\mathrm{NO}_{\mathrm{x}}$ Formation of $\mathrm{OH}$ Radical in Methane-Air Diffusion Flame with Steam Addition. Combustion and Flame, 130:352-360. 


\section{Nomenclature}

\begin{tabular}{|c|l|}
\hline Symbol & Definition \\
\hline $\mathrm{A}$ & Area \\
\hline CGR & Combustion gas recirculation \\
\hline LHV & Lower heating value \\
\hline LMTD & $\begin{array}{l}\text { Log-mean-temperature- } \\
\text { difference }\end{array}$ \\
\hline $\mathrm{m}$ & Mass of gas \\
\hline $\mathrm{Q}$ & Heat transfer \\
\hline $\mathrm{r}$ & Compression ratio \\
\hline $\mathrm{R}$ & Gas constant \\
\hline $\mathrm{T}$ & Temperature \\
\hline $\mathrm{u}$ & Velocity \\
\hline $\mathrm{U}$ & $\begin{array}{l}\text { Heat transfer convection } \\
\text { coefficient }\end{array}$ \\
\hline $\mathrm{W}$ & Work \\
\hline$\lambda$ & $\begin{array}{l}\text { Air-fuel mass ratio/ } \\
\text { Stoichiometric air-fuel mass } \\
\text { ratio }\end{array}$ \\
\hline$\rho$ & Density \\
\hline
\end{tabular}

\begin{tabular}{|c|l|}
\hline Subscript & \\
\hline $\mathrm{c}$ & Compression space \\
\hline $\mathrm{e}$ & Expansion space \\
\hline
\end{tabular}

\begin{tabular}{|c|l|}
\hline Superscript & \\
\hline$\cdot$ & Rate \\
\hline
\end{tabular}


Appendix

Engine Dimensions

\begin{tabular}{|c|c|}
\hline Parameter & Value \\
\hline connecting rod length $(\mathrm{m})$ & $4.600 \mathrm{e}-002$ \\
\hline eccentricity (m) & $2.080 \mathrm{e}-002$ \\
\hline crank radius $(\mathrm{m})$ & $1.380 \mathrm{e}-002$ \\
\hline piston diameter $(\mathrm{m})$ & $10.870 \mathrm{e}-002$ \\
\hline piston length (m) & $5.370 \mathrm{e}-002$ \\
\hline compression clearance volume $\left(\mathrm{m}^{3}\right)$ & $21.47 \mathrm{e}-006$ \\
\hline expansion clearance volume $\left(\mathrm{m}^{3}\right)$ & $202.50 \mathrm{e}-006$ \\
\hline cylinder wall thickness (m) & $3.800 \mathrm{e}-003$ \\
\hline displacer length $(\mathrm{m})$ & $4.350 \mathrm{e}-002$ \\
\hline displacer rod diameter $(\mathrm{m})$ & $0.952 \mathrm{e}-002$ \\
\hline displacer wall thickness $(\mathrm{m})$ & $1.590 \mathrm{e}-003$ \\
\hline cylinder bore clearance $(\mathrm{m})$ & $1.000 \mathrm{e}-004$ \\
\hline appendix gap width (m) & $2.500 \mathrm{e}-004$ \\
\hline cooler inner pipe diameter $(\mathrm{m})$ & $1.080 \mathrm{e}-003$ \\
\hline cooler heat transfer length $(\mathrm{m})$ & $9.000 \mathrm{e}-002$ \\
\hline cooler total pipe length $(\mathrm{m})$ & $10.060 \mathrm{e}-002$ \\
\hline number of cooler tubes & 752 \\
\hline regenerator housing outer diameter $(\mathrm{m})$ & $6.140 \mathrm{e}-002$ \\
\hline regenerator housing inner diameter $(\mathrm{m})$ & $5.740 \mathrm{e}-002$ \\
\hline regenerator length $(\mathrm{m})$ & $2.260 \mathrm{e}-002$ \\
\hline number of regenerators & 8 \\
\hline cooler-to-regenerator manifold length (m) & $0.0807 \mathrm{e}-002$ \\
\hline regenerator-to-heater manifold length $(\mathrm{m})$ & $0.2293 \mathrm{e}-002$ \\
\hline regenerator void volume $\left(\mathrm{m}^{3}\right)$ & $5.030 \mathrm{e}-006$ \\
\hline regenerator matrix void factor & 0.697 \\
\hline wire diameter $(\mathrm{m})$ & $4.000 \mathrm{e}-005$ \\
\hline heater tube inner diameter $(\mathrm{m})$ & $3.020 \mathrm{e}-003$ \\
\hline heater heat transfer length $(\mathrm{m})$ & $26.00 \mathrm{e}-002$ \\
\hline heater total pipe length $(\mathrm{m})$ & $40.08 \mathrm{e}-002$ \\
\hline number of heater tubes & 90 \\
\hline
\end{tabular}

